\title{
An Examination of the Crabtree Effect in Saccharomyces cerevisiae: the Role of Respiratory Adaptation
}

\author{
By J. P. BARFORD* AND R. J. HALL \\ Department of Biological Process Engineering, School of Chemical Engineering, University of \\ New South Wales, Kensington, New South Wales 2033, Australia
}

(Received 9 November 1978)

\begin{abstract}
The control of glycolysis and respiration in a strain of baker's yeast was quantified, including, for the first time, corrections obtained from carbon and redox balances which allowed for interactions between anabolism and catabolism. When these corrections were applied, no repression of respiration was observed during fully adapted growth in continuous culture; however, the rate of respiration reached a maximum value, independent of the nature of the energy substrate, at a specific growth rate less than the maximum specific growth rate of the organism. During batch growth, considerable adaptation was necessary for this organism to achieve its maximum respiratory capacity. Further, this adaptation was extremely slow, particularly when glucose or maltose was the limiting substrate, and its full extent was frequently not achieved. Consequently, a residual repression, presumably originally caused by growth under restricted aeration in shake flasks, was observed during batch growth.
\end{abstract}

\section{INTRODUCTION}

The 'Crabtree Effect' in Saccharomyces cerevisiae has been defined as the repression of respiration, under fully aerobic conditions, in the presence of sugars as a carbon source (De Deken, 1966). Many studies of the control of carbohydrate utilization have made a distinction between inhibition and repression mechanisms (Crabtree, 1929; McGinnis \& Paigen, 1969, 1973). Although both processes occur in the control of carbohydrate utilization, the repression of respiratory enzymes has come to characterize the 'Crabtree Effect' in yeast. Catabolite inhibition may result from the transport of a particular sugar into the cell which causes inhibition of the other sugar transport systems (McGinnis \& Paigen, 1973). Few studies have examined both the activity and amount of key enzymes, procedures necessary for the clear differentiation of the two effects.

Many early workers examined the nature of the sugar source and its effect on the control of respiration (Polakis \& Bartley, 1965; Polakis et al., 1965; Witt et al., 1966; Hommes, 1966; Görts, 1967). However, it would now be generally recognized that the energy flux generated by the carbon source, and not simply the presence of the substrate per se, is the primary cause of repression (Beck \& von Meyenburg, 1968; von Meyenburg, 1969; Suomalainen et al., 1973; Bijkerk \& Hall, 1977; Barford, 1979). Further, any demonstration of a positive control effect requires that the respiratory rate be demonstrably less than the maximum possible rate in the presence of the control effect, that is, in the case of higher substrate supply rates.

Many of the individual biochemical control processes associated with the repression of respiration are now well established. These include the repression of the tricarboxylic acid cycle enzymes and electron transport chain components as well as structural changes to the

* Present address: Department of Chemical Engineering, University of Sydney, Sydney, New South Wales 2006, Australia. 
mitochondria (Strittmatter, 1957; Polakis \& Bartley, 1965; Polakis et al., 1965; Witt et al., 1966; Beck \& von Meyenburg, 1968; Chapman \& Bartley, 1968; Görts, 1971; Ferdouse et al., 1972; Haarasilta \& Oura, 1975). Cyclic AMP levels have been shown to correlate approximately with the level of respiratory repression and gene-cyclic AMP interactions have been described (Fang \& Butow, 1970; Pastan \& Perlman, 1971; Perlman \& Pastan, 1971; Van Wijk \& Konijn, 1971). Such interactions, however, do not describe the basis for the overall coordinated control sequence which leads to the repression of respiration. Hence, whilst the details of many individual biochemical controls associated with the 'Crabtree Effect' have been reported, how these are integrated into the overall metabolism of yeast is unknown (Barford, 1979).

Few attempts have been made to explain the mechanism of this effect and invariably such attempts have introduced concepts relating to the mechanism of integration of the total cell metabolism (von Meyenburg, 1969; Lagunas, 1976; Bijkerk \& Hall, 1977). These have concentrated on the control of total enzymic transcription and translation during the cell cycle, and the division of the total cell mass into anabolic and catabolic cell components under different growth conditions. We have attempted to include many of these concepts into mathematical descriptions of microbial growth (Bijkerk \& Hall, 1977; Pamment et al., 1978; Barford \& Hall, 1979a). An essential aspect of these models is the availability of accurate kinetic data for their evaluation (Barford \& Hall, 1978).

The present work describes some experimental results with a particular strain of baker's yeast over a wide range of experimental conditions using the carbon and redox method that we developed previously (Barford \& Hall, 1979b). It leads to a re-evaluation of many of the traditional views associated with the control of glycolysis and respiration in Saccharomyces cerevisiae.

\section{METHODS}

Organism and growth conditions. Saccharomyces cerevisiae 248 UNSW 703100, a baker's yeast strain (Barford \& Hall, 1976, 1979b; Pamment \& Hall, 1978), was grown on a defined synthetic medium with a sugar or ethanol and $\left(\mathrm{NH}_{4}\right)_{2} \mathrm{SO}_{4}$ as the principal carbon and nitrogen sources, respectively. Culture methods were as described previously (Barford \& Hall, 1976, 1979b; Pamment \& Hall, 1978). The experimental conditions necessary for the accurate measurement of gas exchange and a full description of the novel carbon and redox balance are given by Barford \& Hall $(1979 b)$. For continuous culture experiments, a 2 l cylindrical Quickfit glass fermenter was modified to facilitate more even mixing and included an overflow designed specifically to sample from the bulk of the culture fluid. This eliminated any overflow bias resulting from samples which include considerable quantities of foam. Due to flotation effects, foam may contain a higher concentration of cells resulting in errors in the estimation of culture growth rate. Medium was stored in 201 glass vessels (Duran 50, Schott, Jena glass 201) and pumped to the fermenter by a Sigamotor peristaltic pump (model T8) with a zero-max level controlled gearbox (model UX1) driven by an electric motor (Pacific, model 279).

Preparation of inocula. Inocula were prepared as described previously. They are designated as 'normal' [inocula for batch cultures which were characterized by limited transfer in shake-flask culture (20 to 40 generations) and were large (about $10 \%, \mathrm{v} / \mathrm{v}$ )] or as 'adapted' [inocula for batch cultures which were characterized by extensive transfer in shake-flask culture (100 to 150 generations) and which were small (about $0.05 \%, \mathrm{v} / \mathrm{v}$ )].

Steady-state continuous culture determinations. The organism was initially adapted to a high respiratory capacity at a specific growth rate equal to the maximum respiratory growth rate achieved in batch culture. High growth rate steady-states were monitored for up to 2 to $3 \mathrm{~d}$ (i.e. 30 to 45 generations). This gave the organism a maximum opportunity for any possible respiratory adaptation. In all cases a minimum of 10 fermenter volumes was allowed for the establishment of steady-states, although frequently steady-state results were obtained in shorter periods.

\section{RESULTS}

The strain of baker's yeast used exhibited no repression of respiration in carbon-limited continuous culture since, although the specific oxygen uptake rate (respiratory flux) increased with specific growth rate to a maximum value of 280 to $325 \mathrm{ml} \mathrm{g}^{-1} \mathrm{~h}^{-1}$ at about $0 \cdot 31 \mathrm{~h}^{-1}$, 


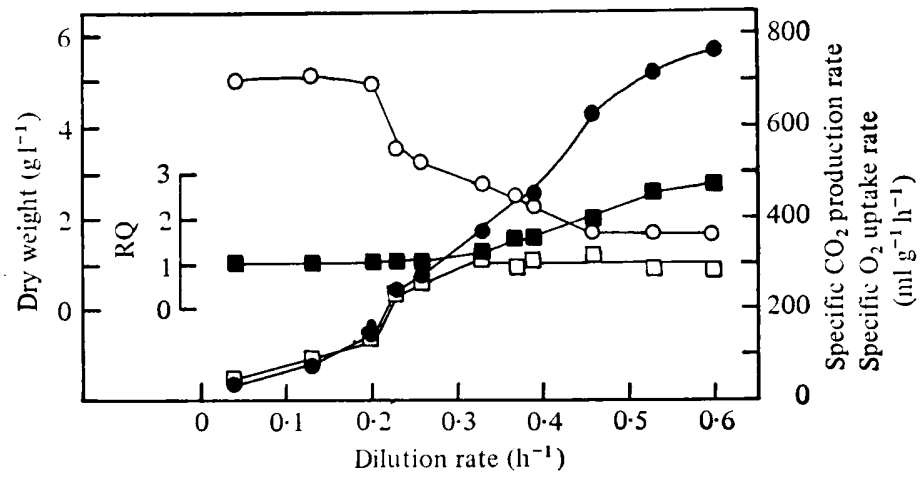

Fig. 1. Continuous culture of $S$. cerevisiae with glucose as the limiting substrate. Estimations were dry weight $(\bigcirc)$, specific carbon dioxide production rate $(\odot)$, specific oxygen uptake rate $(\square)$ and respiratory quotient, RQ ( $\square)$. The glucose feed concentration was $9.93 \mathrm{~g} \mathrm{l}^{-1}$.

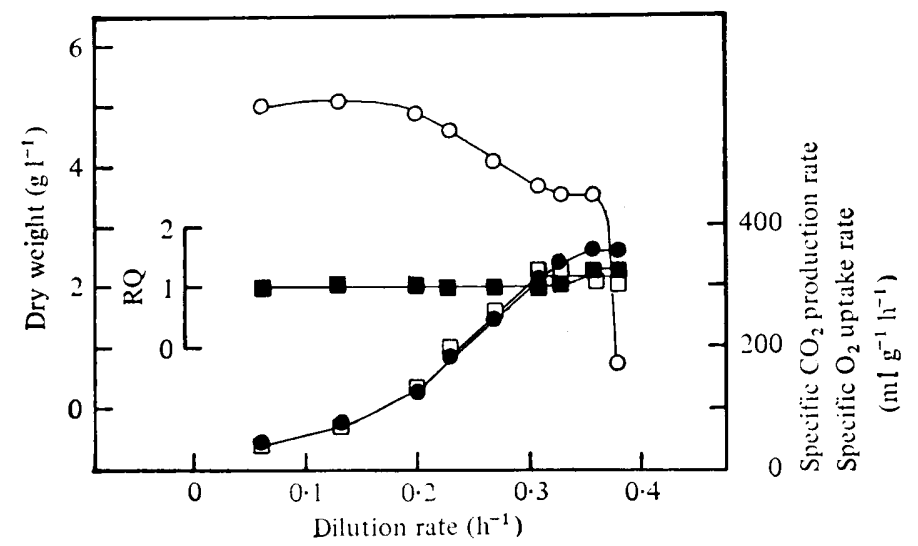

Fig. 2. Continuous culture of $S$. cerevisiae with galactose as the limiting substrate. Estimations were dry weight $(\bigcirc)$, specific carbon dioxide production rate $(\bigcirc)$, specific oxygen uptake rate $(\square)$ and respiratory quotient, RQ $(\mathbf{D})$. The galactose feed concentration was $10 \cdot 11 \mathrm{~g} \mathrm{l}^{-1}$.

there was no reduction in the respiratory flux at high growth rates or energy supply rates (Figs 1 and 2). This was an unexpected result since reported continuous culture data exhibited a decreasing specific oxygen uptake rate (respiratory flux) as the growth rate or energy supply rate was increased above that value at which the respiratory flux reached its maximum value (von Meyenburg, 1969). All other experimental quantities were similar in profile to those normally observed. That is, below a critical specific growth rate of about $0 \cdot 31 \mathrm{~h}^{-1}$, the metabolism of the organism was completely respiratory characterized by a high respiratory cell yield and a respiratory quotient (equal to the specific carbon dioxide production rate divided by the specific oxygen uptake rate) of $1 \cdot 0$. Above this critical specific growth rate, the metabolism of the organism was predominantly glycolytic, characterized by a low cell yield and a respiratory quotient greater than 1.0 (Beck \& Von Meyenburg, 1968; von Meyenburg, 1969).

These results were corrected using methods developed previously (Barford \& Hall, 1979b). The carbon and redox balance indicated that the experimental results were internally consistent. The elemental composition of the cells, biosynthetic oxygen demand and carbon dioxide corrections that were used to fully quantify this effect are presented in Table 1. Significant fluctuations were observed in both the biosynthetic oxygen demand and carbon dioxide corrections. The cause of these variations is unknown. 
Table 1. Experimental data from continuous cultures required for the complete quantification of the control of glycolysis and respiration in S. cerevisiae

\begin{tabular}{|c|c|c|c|c|c|c|c|c|}
\hline \multirow{2}{*}{$\begin{array}{l}\text { Limiting } \\
\text { substrate }\end{array}$} & \multirow{2}{*}{$\begin{array}{l}\text { Dilution } \\
\text { rate } \\
\left(h^{-1}\right)\end{array}$} & \multicolumn{5}{|c|}{ Percentage composition } & \multirow{2}{*}{$\begin{array}{l}\text { Biosynthetic } \\
\mathrm{O}_{2} \text { demand } \\
\left(\mathrm{ml} \mathrm{g} \mathrm{g}^{-1} \mathrm{~h}^{-1}\right)\end{array}$} & \multirow{2}{*}{$\begin{array}{c}\mathrm{CO}_{2} \\
\text { correction } \\
\left(\begin{array}{c}\mathrm{ml} \mathrm{g}^{-1} \\
\left.\mathrm{~h}^{-1}\right)\end{array}\right.\end{array}$} \\
\hline & & $\mathrm{C}$ & $\mathbf{H}$ & $\mathbf{N}$ & $\mathrm{O}$ & Ash & & \\
\hline \multirow[t]{11}{*}{ Glucose } & $0 \cdot 04$ & $41 \cdot 9$ & $6 \cdot 6$ & $6 \cdot 43$ & $35 \cdot 08$ & $9 \cdot 99$ & -1.88 & 0.12 \\
\hline & $0 \cdot 13$ & $44 \cdot 9$ & $6 \cdot 4$ & $7 \cdot 08$ & 32.03 & $9 \cdot 59$ & -6.40 & 0.52 \\
\hline & $0 \cdot 20$ & $43 \cdot 0$ & $6 \cdot 3$ & $7 \cdot 29$ & $34 \cdot 20$ & $9 \cdot 21$ & $-5 \cdot 19$ & $1 \cdot 37$ \\
\hline & $0 \cdot 23$ & $46 \cdot 3$ & $6 \cdot 8$ & $7 \cdot 47$ & $32 \cdot 77$ & 6.66 & -13.93 & $4 \cdot 38$ \\
\hline & 0.26 & $44 \cdot 1$ & $6 \cdot 6$ & $7 \cdot 68$ & $35 \cdot 48$ & $6 \cdot 14$ & $-7 \cdot 56$ & $5 \cdot 27$ \\
\hline & $0 \cdot 33$ & $46 \cdot 3$ & $6 \cdot 8$ & $7 \cdot 82$ & $32 \cdot 80$ & $6 \cdot 28$ & -18.94 & $8 \cdot 73$ \\
\hline & $0 \cdot 37$ & $44 \cdot 6$ & $6 \cdot 6$ & $7 \cdot 99$ & $34 \cdot 32$ & $6 \cdot 49$ & $+15 \cdot 57$ & 5.95 \\
\hline & $0 \cdot 39$ & $45 \cdot 6$ & $6 \cdot 4$ & $7 \cdot 92$ & 33.57 & $6 \cdot 51$ & $-11 \cdot 13$ & $7 \cdot 06$ \\
\hline & 0.46 & $45 \cdot 9$ & $6 \cdot 5$ & $8 \cdot 10$ & $31 \cdot 03$ & $8 \cdot 47$ & $-22 \cdot 86$ & $21 \cdot 21$ \\
\hline & 0.53 & $41 \cdot 4$ & $6 \cdot 2$ & $8 \cdot 37$ & $35 \cdot 29$ & $8 \cdot 74$ & +0.16 & 22.42 \\
\hline & 0.60 & $41 \cdot 3$ & 6.0 & 8.67 & $36 \cdot 73$ & $7 \cdot 30$ & +9.26 & $20 \cdot 20$ \\
\hline \multirow[t]{9}{*}{ Galactose } & 0.06 & $45 \cdot 0$ & 6.6 & 5.66 & $33 \cdot 82$ & 8.92 & $-3 \cdot 90$ & 0.22 \\
\hline & $0 \cdot 13$ & $43 \cdot 8$ & $6 \cdot 7$ & $6 \cdot 28$ & 35.02 & $8 \cdot 20$ & $-7 \cdot 11$ & $0 \cdot 15$ \\
\hline & $0 \cdot 20$ & $41 \cdot 6$ & $6 \cdot 4$ & 6.68 & $37 \cdot 61$ & $7 \cdot 71$ & -3.00 & 0.52 \\
\hline & $0 \cdot 23$ & $45 \cdot 8$ & $6 \cdot 8$ & 6.96 & $33 \cdot 21$ & $7 \cdot 23$ & $-14 \cdot 77$ & 0.84 \\
\hline & 0.27 & $46 \cdot 2$ & $6 \cdot 8$ & $7 \cdot 28$ & $32 \cdot 12$ & $7 \cdot 59$ & $-18 \cdot 52$ & 1.44 \\
\hline & $0 \cdot 31$ & $45 \cdot 8$ & $6 \cdot 6$ & $7 \cdot 41$ & 32.96 & $7 \cdot 23$ & $-15 \cdot 60$ & $1 \cdot 20$ \\
\hline & 0.33 & $45 \cdot 6$ & $6 \cdot 7$ & $7 \cdot 42$ & $32 \cdot 91$ & $7 \cdot 37$ & $-19 \cdot 02$ & 0.85 \\
\hline & 0.36 & $46 \cdot 7$ & $6 \cdot 8$ & $7 \cdot 79$ & $31 \cdot 55$ & $7 \cdot 16$ & -23.93 & 0.89 \\
\hline & 0.38 & $44 \cdot 1$ & $6 \cdot 3$ & $7 \cdot 82$ & $34 \cdot 60$ & $7 \cdot 18$ & $-6 \cdot 21$ & 0.92 \\
\hline
\end{tabular}

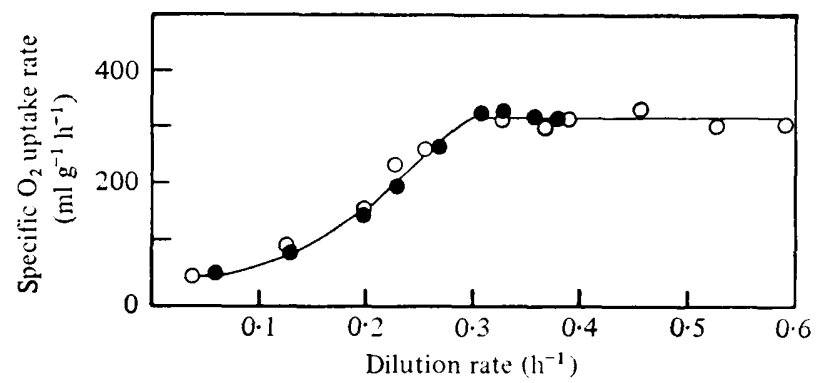

Fig. 3. Combined specific oxygen uptake rate profiles of $S$. cerevisiae grown in continuous culture with glucose and galactose as the limiting substrate. Estimations were specific oxygen uptake rates for glucose $(\bigcirc)$ and galactose $(O)$.

The initial conclusion from these experiments was that this yeast was unusual and did not exhibit repression of respiration. Further (and perhaps more significantly in view of the commonly accepted 'Glucose Effect'), the result that identical respiration rates were obtained in continuous culture with glucose and galactose as the limiting substrates was unexpected (Fig. 3). Any specific 'Glucose Effect' should result in a lower respiratory rate for an organism grown on glucose compared with galactose. This result, consequently, negated any specific 'Glucose Effect' in this organism.

Batch experiments with this same organism, however, indicated that an alternative explanation was possible. In a batch experiment with maltose as the limiting substrate and using an adapted inoculum (see Methods), the specific carbon dioxide production rate, the specific oxygen uptake rate and respiratory quotient were sufficiently constant (Fig. 4) for an estimate to be made of the balanced quantities. The gaseous metabolism profiles of other sugars under identical conditions were also sufficiently constant for balanced quantities to be estimated. This was not the case with normal inocula where the specific carbon 

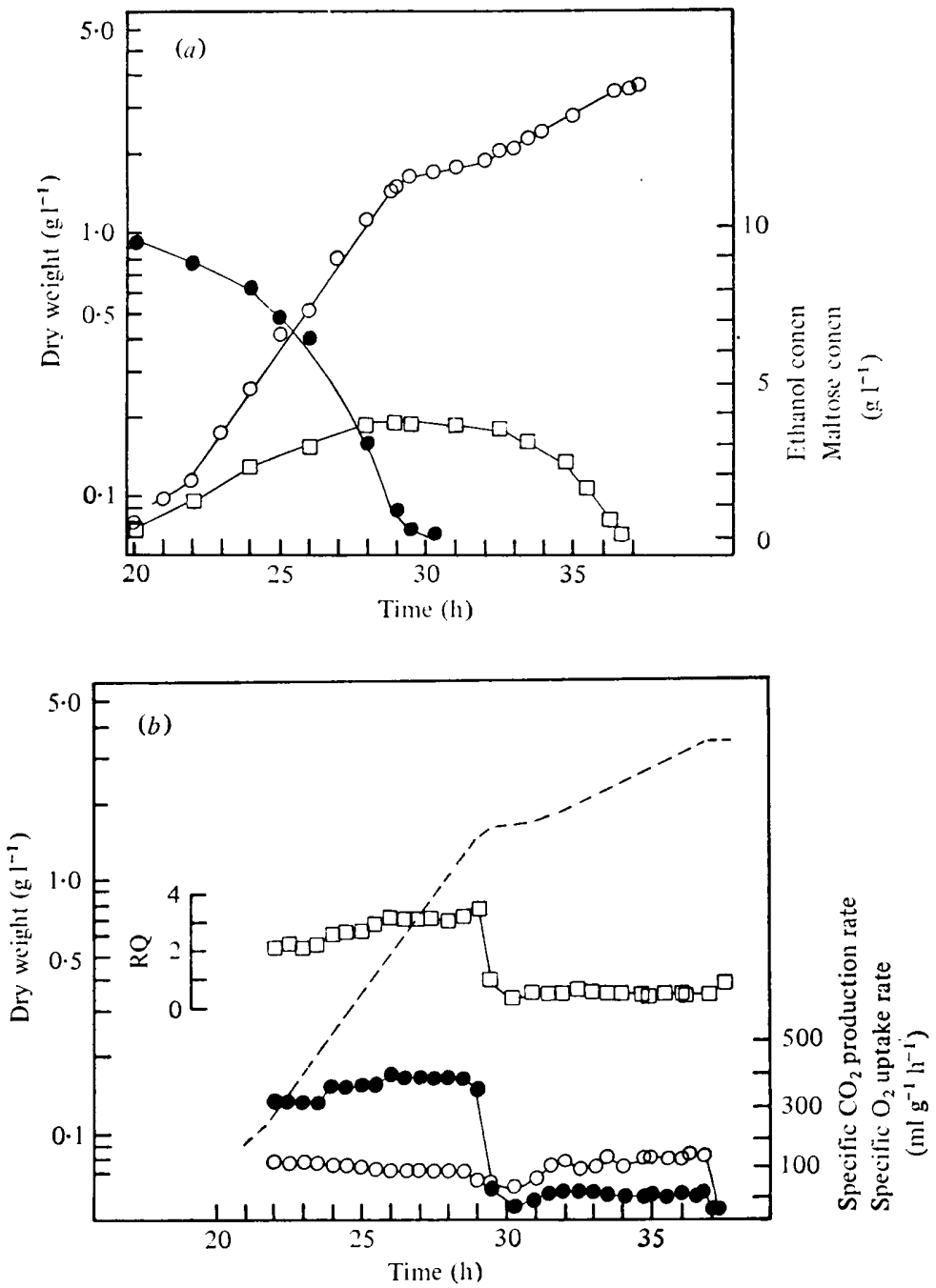

Fig. 4. Batch culture of $S$. cerevisiae, using adapted inocula, with maltose as the limiting substrate. (a) Estimations were dry weight $(\bigcirc)$, maltose concentration $(\Theta)$ and ethanol concentration ( $\square$ ). (b) Estimations were specific carbon dioxide production rate ( $(\mathbf{)})$, specific oxygen uptake rate (O) and respiratory quotient, RQ $(\square)$; the dashed line represents dry weight.

dioxide production rate, the specific oxygen uptake rate and the respiratory quotient were variable and an estimate of the individual balanced specific rates was impossible. More significantly, the exponential specific growth rates were dependent on the degree of adaptation and a considerable capacity for this adaptation existed (Table 2). A similar finding has been reported in Candida utilis although it was not fully quantified (Mian \& Fencl, 1971).

Adapted inocula batch-grown with glucose and maltose (two glucose units) exhibited only small degrees of adaptation. Even with very small, exponential, highly adapted inocula, maltose-grown cultures had the smallest positive adaptation whilst adaptation by glucose-grown cultures was never observed.

It was possible, however, to adapt glucose-grown cultures in continuous culture (Fig. 1) over an extremely long period. At least 50 generations at a specific growth rate equal to the maximum specific growth rate in batch culture $\left(0.45 \mathrm{~h}^{-1}\right)$ were required for this adaptation which was accompanied by a reversible morphological change in which the yeast clumped 
Table 2. Comparison of the sizes of specific growth rate adaptations following different methods of cultivation of $S$. cerevisiae

\begin{tabular}{|c|c|c|c|c|}
\hline \multirow{3}{*}{$\begin{array}{l}\text { Method of culture } \\
\text { Batch }\end{array}$} & & \multicolumn{2}{|c|}{$\begin{array}{l}\text { Specific growth rate }\left(\mathrm{h}^{-1}\right) \\
\text { with different types of inocula }\end{array}$} & \multirow{2}{*}{$\begin{array}{c}\text { Specific } \\
\text { growth rate } \\
\text { adaptation } \\
\quad\left(h^{-1}\right)\end{array}$} \\
\hline & Carbon source & Normal & $\begin{array}{l}\text { Adapted or } \\
\text { steady-state }\end{array}$ & \\
\hline & $\begin{array}{l}\text { Sucrose } \\
\text { Glucose } \\
\text { Maltose } \\
\text { Galactose } \\
\text { Ethanol }\end{array}$ & $\begin{array}{l}0.40 \\
0.45 \\
0.28 \\
0.23 \\
0.05-0.07\end{array}$ & $\begin{array}{l}0.54 \\
0.45 \\
0.36 \\
0.37 \\
0.20\end{array}$ & $\begin{array}{l}0 \cdot 14 \\
0 \\
0 \cdot 08 \\
0 \cdot 14 \\
0 \cdot 13-0 \cdot 15\end{array}$ \\
\hline Continuous & $\begin{array}{l}\text { Glucose } \\
\text { Galactose }\end{array}$ & $\begin{array}{l}(0 \cdot 45) \\
(0 \cdot 23)\end{array}$ & $\begin{array}{l}0.60 \\
0.38\end{array}$ & $\begin{array}{l}0 \cdot 15 \\
0 \cdot 15\end{array}$ \\
\hline
\end{tabular}

Table 3. Comparison of specific oxygen uptake rates of adapted inocula batch cultures and the maximum specific oxygen uptake rates of continuous cultures for $S$. cerevisiae

$\begin{array}{ccc}\text { Method of culture } & \text { Carbon source } & \begin{array}{c}\text { Specific } \mathrm{O}_{2} \text { uptake } \\ \text { rate }\left(\mathrm{ml} \mathrm{g}^{-1} \mathrm{~h}^{-1}\right)\end{array} \\ \text { Batch (adapted inocula) } & \text { Sucrose } & 252 \cdot 23 \\ & \text { Glucose } & 150 \cdot 85 \\ & \text { Maltose } & 168 \cdot 47 \\ & \text { Galactose } & 254 \cdot 74 \\ \text { Ethanol } & 185 \cdot 70 \\ \text { Continuous } & \text { Glucose } & 280 \cdot 16-315 \cdot 32 \\ & \text { Galactose } & 297 \cdot 64-322 \cdot 83\end{array}$

into closely packed units. This morphological change has been observed with other baker's yeast strains (Humphrey, 1973). It was accompanied by an increase in the maximum specific growth rate to $0.6 \mathrm{~h}^{-1}$. When the degree of this specific growth rate adaptation was compared with the other batch specific growth rate adaptations, they were of the same order of magnitude. This is illustrated in Table 2 by the magnitude of the differences between specific growth rates using adapted or steady-state and normal inocula.

The comparative specific oxygen uptake rates exhibited by the adapted batch cultures and the continuous cultures were indicative of the degree of respiratory adaptation of the culture (Table 3). The full range of experimental data necessary for the quantification of the adapted inocula batch experiments and the average specific gas exchange rates are given in Table 4.

\section{DISCUSSION}

The most significant finding arising from this work was that, for the baker's yeast strain used here, the repression of respiration observed during batch growth was a consequence of a very slow adaptation to a fully respiratory condition. In carbon-limited continuous culture, where sufficient time was available for this adaptation, no repression of respiration was observed with either glucose or galactose as the carbon source. Any effects due to mutation were not considered since it was possible to obtain normal specific growth rates when normal inocula were prepared from batch and continuous cultures which had undergone adaptation. The rate of respiration was the same for both sugars and was shown to saturate to a constant value at a dilution rate of about $0.31 \mathrm{~h}^{-1}$. This was in sharp contrast with the data of von Meyenburg (1969) which clearly indicated a repression of respiratory activity at growth rates above a critical dilution rate.

The original cause of the repression observed in batch growth was presumed to be prior growth under restricted aeration in shake-flasks. It seems unlikely that the repression is 

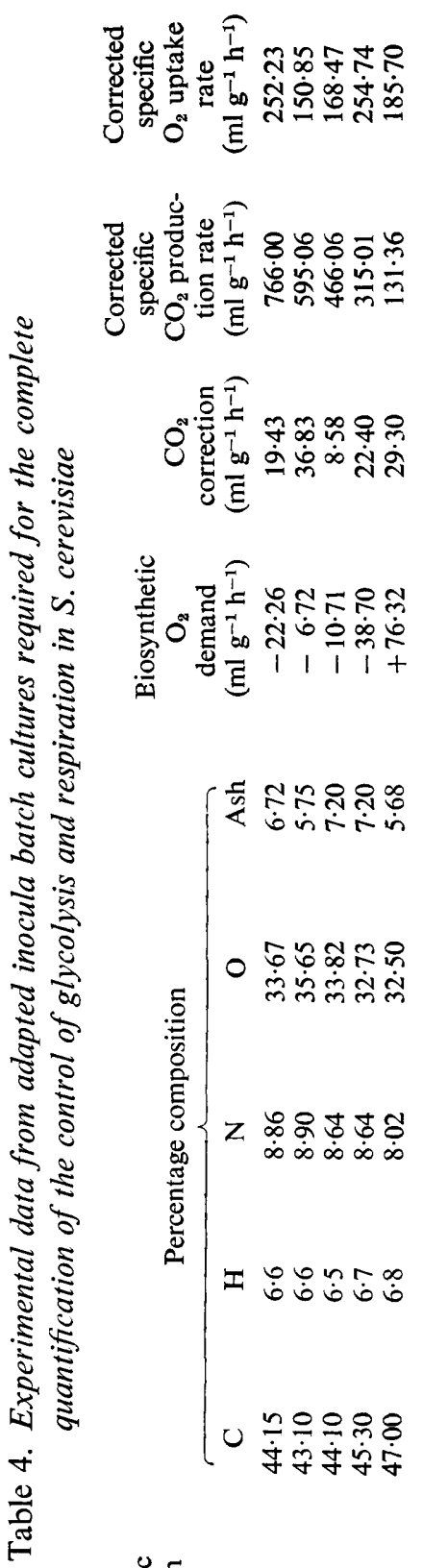

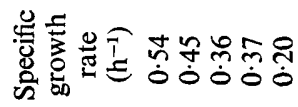

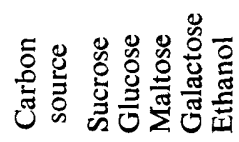


caused by high sugar concentrations or supply rates since, given sufficient time at high glucose supply rates in continuous culture, the organisms exhibited full respiratory capacity. These results nevertheless do not eliminate the possibility that repression is caused by sugar concentrations higher than those obtained in carbon-limited continuous culture although comparison of galactose and glucose batch and continuous culture experiments would suggest that this was unlikely.

The generality of this response is unknown but under investigation. Whilst it is unlikely that the more extensive studies reporting the 'Crabtree Effect' (von Meyenburg, 1969) were artefactual, the number of studies actually reporting this effect in sufficient detail is relatively small. Much of the reported work has one or more of the following limitations. (1) Data was collected under only one growth condition; this is clearly inadequate (De Deken, 1966; Johnson et al., 1972). (2) Reliance was placed on data from washed suspensions without evidence that the results were relevant to normal growth conditions (Hommes, 1966; Görts, 1967; Fales, 1960; Beran \& Zemanova, 1969; Hoogerheide, 1971; Johnson et al., 1972; Silhankova et al., 1975). (3) There was a failure to achieve balanced growth under batch conditions (Beck \& von Meyenburg, 1968; von Meyenburg, 1969) or to provide sufficient detail to substantiate the existence of balanced growth (De Deken, 1966; Kuenzi \& Fiechter, 1969; Görts, 1971; Silhankova et al., 1975; Lagunas, 1976). (4) Large random and systematic errors in the estimation of gas exchange data are possible unless very careful techniques are used (Fiechter, 1975; Barford \& Hall, 1979 b). Some studies have used inaccurate techniques such as indirect methods of estimating oxygen uptake (Hommes, 1966; Stein \& Iditoiu, 1971). The difficulty of measuring oxygen uptake rates is such that an independent assessment of the accuracy is required. An overall carbon and redox balance, described in detail elsewhere (Barford \& Hall, 1979 b), provides such an independent assessment and was used in this work for the first time for the study of the 'Crabtree Effect'.

When these reservations regarding the data in the literature are taken into account and it is recognized that similar responses to those reported here have been observed for S. cerevisiae (Bijkerk, 1975) and C. utilis (Mian et al., 1974), it is clear that further work is necessary to determine the generality of either response.

Finally, this work demonstrates the importance of a careful analysis, based on an overall carbon and redox balance of data collected over a range of experimental conditions. Only such an approach can generate reliable and accurate data upon which to base proposals regarding the control of glycolysis and respiration.

\section{REFERENCES}

BARFORD, J. P. (1979). Microbial growth models. Ph.D. thesis, University of New South Wales, Australia.

BARFORD, J. P. \& HALL, R. J. (1976). Estimation of the length of cell cycle phases from asynchronous culture of Saccharomyces cerevisiae. Experimental Cell Research 102, 276-284.

Barford, J. P. \& HALl, R. J. (1978). An evaluation of the approaches to the mathematical modelling of microbial growth. Process Biochemistry 13(8), 22-29.

BARFORD, J. P. \& HALL, R. J. (1979a). Simulation of the internal metabolic rates of Saccharomyces cerevisiae. Seventh National Conference on Chemical Engineering, Chemeca 79, Newcastle, Australia, pp. 21-25.

BARFORD, J. P. \& HALL, R. J. (1979b). Investigation of the significance of a carbon and redox balance to the measurement of gaseous metabolism in Saccharomyces cerevisiae. Biotechnology and Bioengineering 21, 609-626.
Beck, C. \& von Meyenburg, H. K. (1968). Enzyme pattern and aerobic growth of Saccharomyces cerevisiae under various degrees of glucose limitation. Journal of Bacteriology 96, 479-486.

Beran, K. \& Zemanova, J. (1969). Cell growth and population activity of Saccharomyces cerevisiae in two-stage continuous cultivation. Biotechnology and Bioengineering 11, 853-862.

BIJKERK, A. H. E. (1975). The dynamics of yeast growth. Ph.D. thesis, University of New South Wales, Australia.

BiJKerk, A. H. E. \& HALl, R. J. (1977). A mechanistic model of the aerobic growth of Saccharomyces cerevisiae. Biotechnology and Bioengineering 19, 267-296.

Chapman, C. \& Bartley, W. (1968). The kinetics of enzyme changes in yeast under conditions that cause the loss of mitochondria. Biochemical Journal 107, 455-465. 
Crabtree, H. G. (1929). Observations on the carbohydrate metabolism of tumours. Biochemical Journal 23, 536-545.

De Deken, R. H. (1966). The Crabtree Effect: a regulatory system in yeast. Journal of General Microbiology 44, 149-156.

FALES, F. W. (1960). The aerobic assimilation of glucose by yeast cells. Journal of Biological Chemistry 235, 1255-1257.

FANG, M. \& Butow, R. A. (1970). Nucleotide reversal of mitochondrial repression in Saccharomyces cerevisiae. Biochemical and Biophysical Research Communications 41, 1579-1583.

Ferdouse, M., Rickard, P. A. D., Moss, F. J. \& Blanch, H. W. (1972). Quantitative studies of the development of $S$. cerevisiae mitochondria. Biotechnology and Bioengineering 14, 1007-1026.

FieCHTER, A. (1975). Methods in Cell Biology, 1st edn, p. 131. New York \& London: Academic Press.

GörTs, C. P. M. (1967). Effect of different carbon sources on the regulation of carbohydrate metabolism in Saccharomyces cerevisiae. Antonie van Leeuwenhoek 33, 451-463.

GöRTs, C. P. M. (1971). Some aspects of catabolite repression of mitochondrial enzymes in Saccharomyces cerevisiae. Antonie van Leeuwenhoek 37, 161-169.

HaARasilta, S. \& Oura, E. (1975). On the activity regulation of anaplerotic and gluconeogenetic enzymes during the growth phases of baker's yeast. European Journcil of Biochemistry 52, 1-7.

Hommes, F. A. (1966). Mechanism of the Crabtree Effect in yeast grown with different glucose concentrations. Archives of Biochemistry and Biophysics 113, 324-330.

HoOGERHEIDE, J. C. (1971). On the disturbance of the normal Pasteur reaction in baker's yeast. Antonie van Leeuwenhoek 37, 435-448.

Humphrey, A. E. (1973). Biochemical Engineering, 2nd edn, p. 151. Edited by S. Aiba, A. E. Humphrey \& N. F. Millis. New York \& London: Academic Press.

Johnson, N., Nelson, S. J. \& Brown, C. M. (1972). Influence of glucose concentration on the physiology and lipid composition of some yeasts. Antonie van Leeuwenhoek 38, 129-136.

KuenZI, M. T. \& Fiechter, A. (1969). Changes in carbohydrate composition and trehalase activity during the budding cycle of Saccharomyces cerevisiae. Archiv für Mikrobiologie 64, 396-467.

LAGUNAS, R. (1976). Energy metabolism of Saccharomyces cerevisiae. Discrepancy between ATP balance and known metabolic functions. Biochimica et biophysica acta 440, 661-674.

Meyenburg, H. K. von (1969). Katabolit-Repression und der Sprossungszyklus von Saccharomyces cerevisiae. Ph.D. thesis, Eidgenössische Technische Hochschule, Zurich.
McGinnis, J. F. \& Paigen, K. (1969). Catabolite inhibition: a general phenomenon in the control of carbohydrate utilization. Journal of Bacterio$\log y$ 100, 902-913.

MCGinNis, J. F. \& PAigen, K. (1973). Site of catabolite inhibition of carbohydrate metabolism. Journal of Bacteriology 114, 885-887.

Mian, F. A. \& FeNCL, Z. (1971). Growth and physiology of a yeast cultivated in batch and continuous culture systems. Folia microbiologica 16, 249-259.

Mian, F. A., Fencl, Z., Prokop, A., Mohagheghi, A. \& FAZELI, A. (1974). Effect of growth rate on the glucose metabolism of yeast grown in continuous culture. Radiorespirometric studies. Folia microbiologica 19, 191-198.

Pamment, N. B. \& Hall, R. J. (1978). Absence of external causes of lag in Saccharomyces cerevisiae. Journal of General Microbiology 105, 297-304.

Pamment, N. B., Hall, R. J. \& Barford, J. P. (1978). Mathematical modelling of the lag phases in microbial growth. Biotechnology and Bioengineering 20, 249-281.

Pastan, I. \& Perlman, R. L. (1971). Cyclic AMP in metabolism. Nature New Biology 229, 5-7.

Perlman, R. L. \& Pastan, I. (1971). The role of cyclic AMP in bacteria. Current Topics in Cellular Regulation 3, 117-134.

Polakis, E. S. \& Bartley, W. (1965). Changes in enzyme activities of Saccharomyces cerevisiae during growth on different carbon sources. Biochemical Journal 97, 284-297.

Polakis, E. S., Bartley, W. \& Meek, J. A. (1965). Changes in the activities of respiratory enzymes during the aerobic growth of yeast on different carbon sources. Biochemical Journal 97, 298-302.

Silhankova, L., Mostek, J. \& Pizingerova, A. (1975). Metabolic quotients of respiration-deficient mutants of brewer's yeast and the appearance of a negative Pasteur effect. Journal of the Institute of Brewing 81, 219-224.

Stein, E. \& Iditoiu, C. (1971). Studies of the Crabtree effect in yeast. Revue roumaine de biochimie 8, 335-342.

Strittmatter, C. A. (1957). Adaptive variation in the level of oxidative activity in Saccharomyces cerevisiae. Journal of General Microbiology 16, 169-183.

Suomalainen, H., Nurminen, T. \& Oura, E. (1973). Progress in Industrial Microbiology 12, 109-167.

VAN WiJK, R. \& KoniJn, T. M. (1971). Cyclic 3',5'-AMP in Saccharomyces carlsbergensis under various conditions of catabolite repression. FEBS Letters 13, 184-186.

WitT, I., KronaU, R. \& Holzer, H. (1966). Repression von Alkoholdehydrogenase, Malatdehydrogenase, Isocitratlyase und Malatsynthase in Hefe durch Glucose. Biochimica et biophysica acta 118, 522-537. 